'Joe Camel' advertising campaign. Indeed, one former tobacco lobbyist - now suffering from throat cancer he attributes to years of smoking - has described meetings where his tobacco industry colleagues discussed new ways to attract young smokers to replace older ones who were dying.

Ultimately, based on a voluminous accumulation of evidence, the agency decided that nicotine is indeed an addictive drug. Among other things, research reviewed by the FDA showed that smokers who try to quit suffer physical and psychological withdrawal symptoms, such as decreased heart rate, insomnia, irritability, lack of concentration and anxiety, which are all signs of drug dependence.

Also, Jack Henningfield, chief of the clinical pharmacology research branch of the National Institute on Drug Abuse, has pointed out that approximately one-third or more of smokers try to quit every year and "only about 7 percent make it." The 40 million people in the United States who have successfully stopped smoking represent only 2.5 percent per year since 1964 , according to Henningfield.

The FDA also concluded that it had dual authority under its medical device statutes because cigarettes themselves are 'drug delivery systems', making them what the agency calls 'combination products'.

The proposals are subject to public comment and revision, and could take a year or more to implement. Challenges are certain. The friends of tobacco on Capitol Hill have promised to push for legislation that would remove the FDA's jurisdiction over tobacco. One measure currently being drafted would transfer it to the Federal Trade Commission and the US Attorney General.

Predictably, the nation's five major tobacco companies and an advertising agency have filed a lawsuit in a North Carolina court. Unlike product liability cases, however, which in the past have favoured industry, the courts traditionally have deferred to the agencies on questions of jurisdiction.

Matthew Myers, counsel to the Coalition on Smoking OR Health, one of the anti-smoking groups that first urged FDA action, predicts that the litigation could take two or three years, although the courts might well allow the FDA's proposals to go forward in the interim.

"I assume this one will reach the [US] Supreme Court," Myers says, "because the industry will never give up."

Marlene Cimons Washington, $D C$

\title{
India refining simple HIV test
}

Scientists at Delhi University have developed a simple blood test that is said to detect antibodies to the human immunodeficiency virus (HIV) in seconds. The simplicity of the test and its low cost should make it a valuable tool in the battle against AIDS, especially in poor countries that lack health-care infrastructure. (India has more than 22,000 HIV-positive individuals, according to official estimates.)

But the university scientists, who are now refining the test, are in no hurry to market it until they can be sure that it detects both HIV-1 and HIV-2 with reliability. This may take six months.

Besides being expensive, conventional enzyme-linked immunosorbent assays (ELISAs) involve multiple steps and require trained technicians, centrifuges and ELISA readers, and, as a consequence, a source of electricity. Sample processing can also take hours.

The new test uses whole blood, thereby eliminating the need for time-consuming separation steps. All that is required for diagnosis is a glass slide and a reagent prepared through recombinant DNA technology, which the government's Department of Biotechnology - the project's sponsor - is hoping to patent.

The single-step test involves adding a drop of the reagent to a drop of blood on a slide and mixing the two. Results are obtained within 5-10 seconds. If the red blood cells clump, the test is positive.

"Rapidity and simplicity are the main virtues of this test," says Vijay $K$. Chaudhary, who developed it in collaboration with Shobha Sehgal of the
Postgraduate Institute for Medical Education and Research in Chandigarh. Chaudhary wants to test at least 2,000 samples before commenting on sensitivity and specificity, but in a limited trial of 100 samples, he says it failed only once.

Most of India's 1,100 blood banks do not screen blood for want of imported kits or because of non-functioning equipment. Only two months ago, the government ordered the closure of a blood bank in Bombay run by the Indian Red Cross Society after learning that it had been supplying tainted blood to city hospitals for as long as two years.

The key to the new test is the recombinant reagent, a fusion protein obtained by fusing an antibody fragment, which binds to the surface of red blood cells, with a synthetic peptide antigen corresponding to the gp4l sequence in the HIV-1 envelope. HIV-1 antibody, if present in the blood sample, binds to the peptide portion of the fusion protein, causing crosslinking between red blood cells and visible agglutination.

Although Chaudhary has received many offers to commercialize the new test, he prefers instead to wait until his team is able to make a 'cocktail' of fusion proteins carrying all the other antigens of HIV-1, and those of HIV-2. The government, which has so far spent $\$ 150,000$ on Chaudhary's work, has sanctioned a further $\$ 100,000$ for development of other fusion proteins. Work on this is under way and Chaudhary expects to have a commercially available test next year.

K.S. JAYARAMAN New Delhi

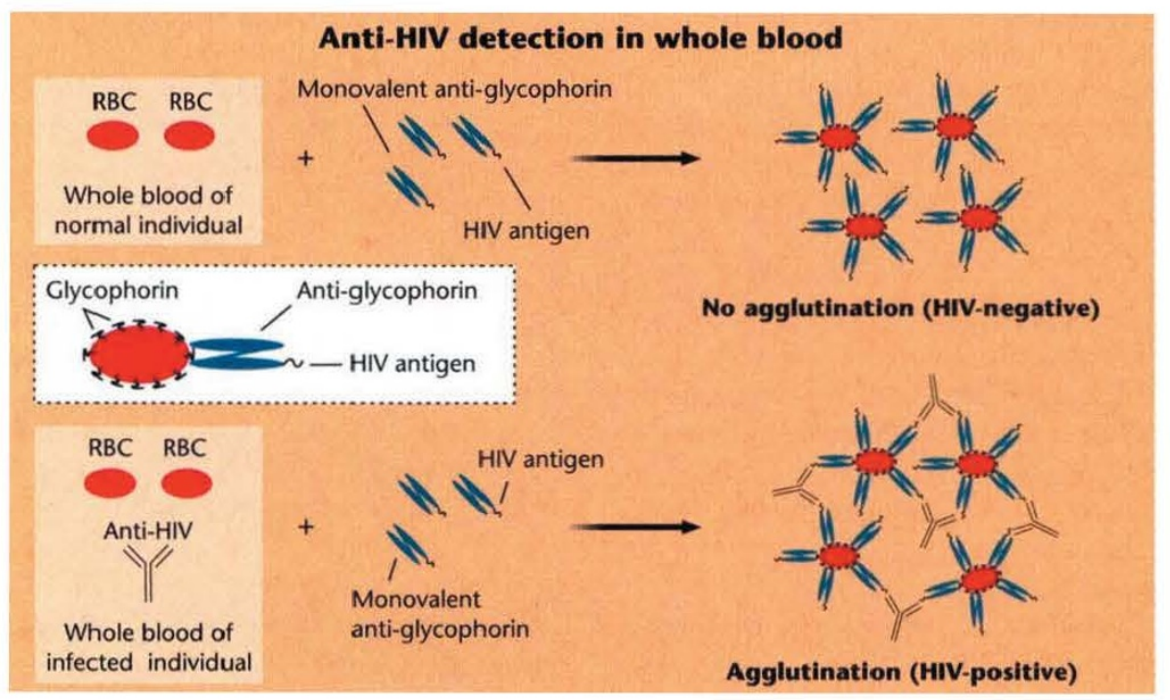

